\title{
Number of Pelvic Lymph Nodes Positive for Tumor by H\&E
}

National Cancer Institute

\section{Source}

National Cancer Institute. Number of Pelvic Lymph Nodes Positive for Tumor by H\&E. NCI Thesaurus. Code C158648.

A request to specify the number of pelvic lymph nodes found positive for tumor by $\mathrm{H} \& \mathrm{E}$. 